\title{
Tipps und Tricks: Duschen mit Fixateur externe
}

\author{
口 Dankward Höntzsch
}

Beim Fixateur externe ist die Pin-Pflege eine immerwährende Diskussion.

Es gibt viele verschiedene Methoden, von ganz einfachen bis sehr komplexen. Viel wichtiger ist aber, die richtige Positionierung der Schanz-Schrauben, die Positionierung des Schnitts zum Pin und dass die Pins nicht in „verbotenen“ Zonen liegen. Dann ist nur sehr wenig Aufwand für die Pin-Pflege notwendig. Eine Pin-Pflege kann eine ungünstige Positionierung des Pins nicht kompensieren.

Wenn von dieser Seite alles richtig gemacht ist, kann empfohlen werden, dass mit einem Fixateur externe geduscht werden kann! Von den Experten, die sehr viele Fixateur externe, auch lang liegende, anwenden, wird dies dringend empfohlen. Dies ist für die Pin-Eintrittstelle nur von großem Vorteil. Dazu kommt der psychologische Effekt. Diesen Vorgang zu empfehlen, ist deshalb wichtig, weil es bis heute und immer wieder vonseiten der Ärzte und Pflege gegen diese Methode Widerstände und Unverständnis gibt.

Eine Bilderserie soll zeigen, dass man duschen oder baden kann. Es darf auch Seife oder Sonstiges benutzt werden. Aus Rücksicht $\mathrm{zu}$ anderen Badenden sollte nicht in öffentlichen Frei- und Hallenbädern gebadet werden. Das Mittelmeer (oder andere Meere oder Seen) kann empfohlen werden.
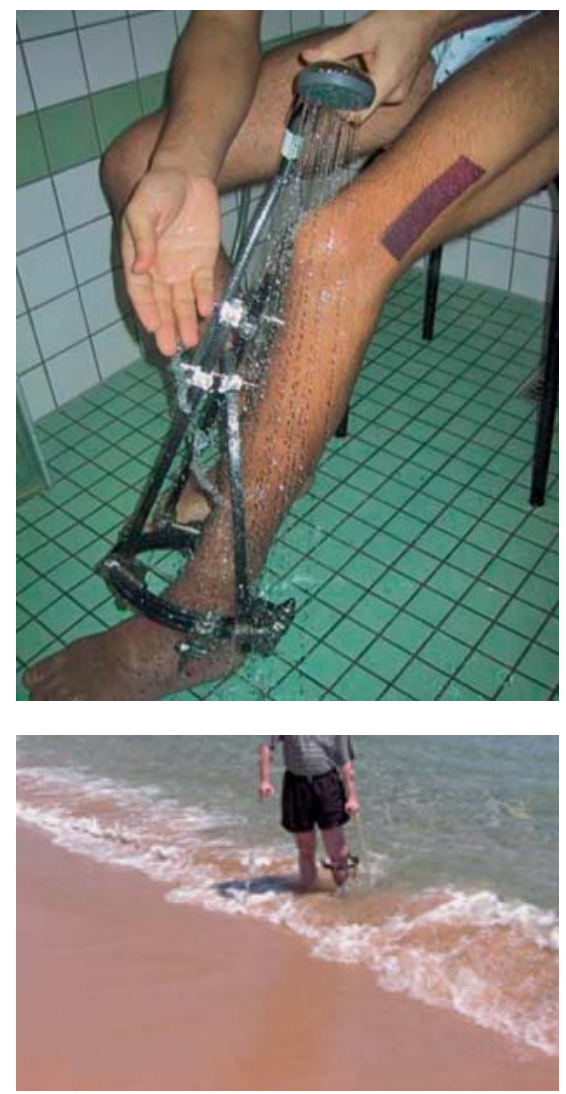
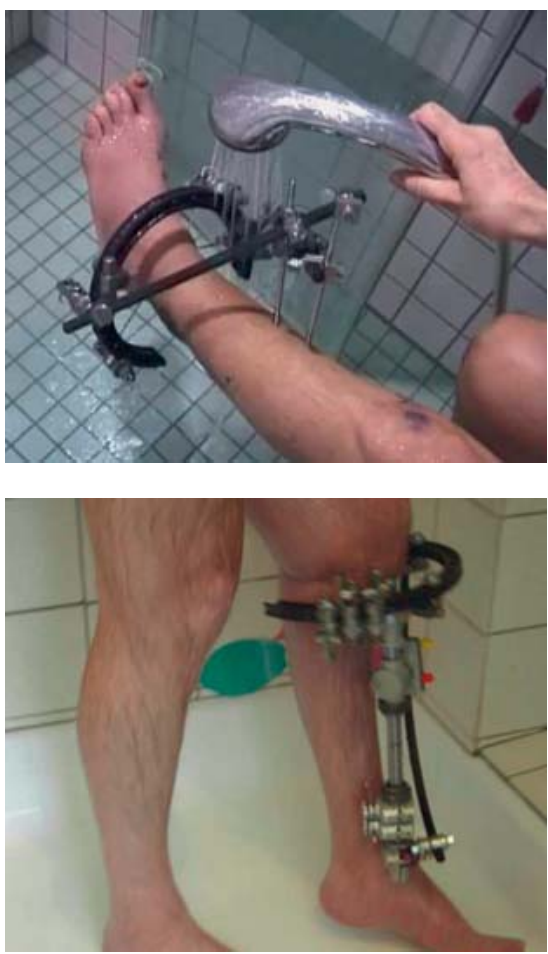

OP-JOURNAL 2016; 32: 161

(c) Georg Thieme Verlag KG Stuttgart · New York DOI http://dx.doi.org/10.1055/s-0042-117124 